\title{
A Miniaturized Biaxial Deformation Rig for in Situ Mechanical Testing
}

\author{
S. Van Petegem ${ }^{1}$ - A. Guitton ${ }^{1,2} \cdot$ M. Dupraz ${ }^{1}$ - A. Bollhalder ${ }^{3} \cdot$ K. Sofinowski ${ }^{1,4}$. \\ M.V. Upadhyay ${ }^{1}$ • H. Van Swygenhoven ${ }^{1,4}$
}

Received: 19 August 2016 / Accepted: 30 November 2016 / Published online: 26 January 2017

(C) The Author(s) 2017. This article is published with open access at Springerlink.com

\begin{abstract}
A novel miniaturized biaxial deformation rig is presented. It allows one to apply in-plane biaxial stress states with arbitrary stress ratios and to perform strain path changes on thin-sheet metals. The device is optimized for in situ usage inside a scanning electron microscope and at synchrotron beam lines. The sample has a cruciform shape and the geometry is optimized with the aid of finite element simulations. A proof-of-principle experiment confirms the successful operation of this rig.
\end{abstract}

Keywords Biaxial deformation · Strain path changes · In situ X-ray diffraction $\cdot$ Scanning electron microscope

\section{Introduction}

Most of the industrial metal sheet forming operations such as drawing, stamping or stretch forming, subject materials to a wide range of successive uniaxial and/or biaxial strain paths including sudden strain path changes. Changes in strain path directions can have a significant effect on the mechanical re-

H. Van Swygenhoven

helena.vanswygenhoven@psi.ch

S. Van Petegem

Steven.VanPetegem@psi.ch

A. Guitton

Antoine.Guitton@univ-lorraine.fr

M. Dupraz

Maxime.Dupraz@psi.ch

A. Bollhalder

Alex.Bollhalder@psi.ch

K. Sofinowski

Karl-Alan.Sofinowski@psi.ch sponse of metals. When a metallic material is plastically reloaded following a previous deformation path, significant changes in the reloading yield stress and hardening evolution might occur depending on the mode and direction of reloading [1-5]. Our understanding of the micromechanical behaviour of a material is mainly derived from uniaxial deformation tests including $180^{\circ}$ strain path changes (load-unload). It is however widely accepted that deformation properties of metals under multiaxial loading conditions are different than those predicted by uniaxial tests $[6,7]$.

Furthermore, the final microstructure and residual stress state obtained after a multiaxial deformation history will be different from those expected from solely uniaxial deformation. Measuring and understanding the residual stress is of capital importance because of its role in predicting the lifespan of engineering materials under service conditions. To understand how a macroscopic component will behave under a multiaxial load, it is necessary to identify the fundamental mechanisms driving multiaxial deformation and how they differ from the uniaxial case. Most research in the last two decades has focused on gathering

M.V. Upadhyay
Manas.Upadhyay@psi.ch

1 Swiss Light Source, Paul Scherrer Institut, 5232 Villigen PSI, Switzerland

2 Present address: LEM3, UMR CNRS 7239, University of Lorraine, Île du Saulcy, 57045 Metz, France

3 Laboratory for Developments and Methods, NUM, Paul Scherrer Institut, 5232 Villigen PSI, Switzerland

4 Neutrons and X-rays for Mechanics of Materials, IMX, École Polytechnique Fédérale de Lausanne, 1012 Lausanne, Switzerland 
macroscopic multiaxial mechanical properties combined with post-mortem characterization techniques such as electron microscopy, X-ray diffraction and fractography analysis (see, for instance, ref. [8-13]). However, a thorough understanding of the deformation mechanisms under multiaxial conditions and/or during strain path changes requires the use of in situ techniques that allow the real time tracking of the microstructural evolution. This calls for a device that 1 ) allows applying various multiaxial stress states, 2) can perform strain path changes and 3) can be used in situ in a microscope and/or at a synchrotron/neutron source.

Several multi-axial deformation setups have been developed for the deformation of sheet metal. This includes bulge pressure tests [14, 15], flat punch [16, 17], hemi-spherical punch [18], multiaxial compression tests [19] and cruciform tests [20-26], each with their own specific strengths and weaknesses. For low and moderate levels of plastic deformation the cruciform tests are the most versatile option since they allows applying in-plane biaxial stresses with arbitrary ratios of the stresses along the principal directions and to perform strain path changes. Furthermore they avoid complications with contact or friction. If large plastic strains are required then the Marciniak test $[16,17]$ is considered to be the preferred method.

A few multi-axial setups have been developed specifically for in situ applications that allow obtaining information on local lattice strains or microstructural changes. X-ray diffraction (XRD) at the laboratory scale combined with the Raghavan modified version of the Marciniak test [27-29] was developed to measure lattice distortions in multiaxial strained sheet metal samples under load. Local stresses are derived from the lattice strains assuming an isotropic constitutive law. A similar method has been applied to measure the local stress state during in-plane biaxial deformation of cruciform shaped specimens [30]. In order to track damage evolution during deformation of sheet metal subjected to various strain paths up to the point of fracture a miniaturized Marciniak setup for in situ electron scanning microscopy (SEM) observations was developed. Combined with digital image correlation the applied strain can be followed together with deformation induced microstructural changes at the surface $[11,31]$. For studying thin films deposited on a polymer substrate, a miniaturized biaxial deformation rig using a polymer cruciform sample geometry can be used in situ at the DIFFABS beam line at the SOLEIL synchrotron $[32,33]$. A device using a uniaxial deformation rig and a biaxial loading mechanism [34] has been used at the I12 beam line of the Diamond Light Source allowing to deform cruciform samples with various biaxial load ratios [35]. A biaxial deformation rig installed at the engineering neutron diffractometer POLDI of the Swiss Spallation Neutron Source [24] allows applying inplane biaxial stress states with flexible stress ratios combined with strain path changes on thick cruciform shape metals during neutron diffraction [24]. Recently, a new setup rig was developed at the Advanced Photon Source (APS, 1-IDE) that allows combining far-field-high-energy diffraction microscopy with in situ planar biaxial loading experiments [36].

Each of these devices has its strengths and weaknesses. However, only the rigs based on cruciform shaped samples exhibit the necessary flexibility that allow performing in situ diffraction experiments while applying both proportional and non-proportional multiaxial stress states combined with strain path changes. Furthermore, it is often the case that materials are not available in large quantities, or cannot be deposited on a substrate. This paper presents a novel miniaturized biaxial deformation rig that is dedicated to in situ mechanical testing in an SEM and at the synchrotron. It is based on cruciform shaped specimens with dimensions in the range of a few tens of millimetres and thicknesses of the order of a hundred micrometre. In the following sections we present the design concept of the rig and the sample geometry, followed by characterization tests and finally a proof-of-principle experiment.

\section{New in Situ Biaxial Testing Apparatus}

\section{Design Concept}

The conceptual design of the new biaxial in-plane tensile testing apparatus is illustrated in Fig. 1, the corresponding relevant parameters are provided in Table 1. A cruciform shaped specimen is mounted on 4 grips with the aid of cylindrical shaped pins that are slightly tilted outwards from the centre of the apparatus. This ensures that the specimen is pushed down onto the grips during pulling. The 4 grips are sliding inside a guide system, ensuring a good alignment between loading axes and the grips. Each grip is connected to a load cell (MLP-10, Transducer Techniques) with a capacity of $44 \mathrm{~N}$ and a safe overload of $150 \%$. The use of 4 load cells ensures a fully symmetric setup and, as a consequence, identical compliance of all 4 axes and proper sample alignment while applying a biaxial load. Via a carrier plate the load cells, grips and guide systems are connected to 4 piezo actuators (N-111 Nexline, PI). Each individual actuators allow for step sizes between $10 \mathrm{~nm}$ and $10,000 \mathrm{~nm}$ with a total travel range of $10 \mathrm{~mm}$ and maximum velocity of $0.4 \mathrm{~mm} / \mathrm{s}$. Furthermore the actuators can pull up to a $50 \mathrm{~N}$ force. In other words, these actuators combine large travel range with nanometre step size and can work under relatively high forces, which is crucial for the compact design of the apparatus. 8 optical limit switches (two per axis) ensure that the grips do not crash into each other. It should be noted that the system as shown in Fig. 1 was designed solely for biaxial tensile experiments. However, it is in principle also possible to perform biaxial compression experiments by replacing the grips with appropriate compression heads. 
(a)

(b)

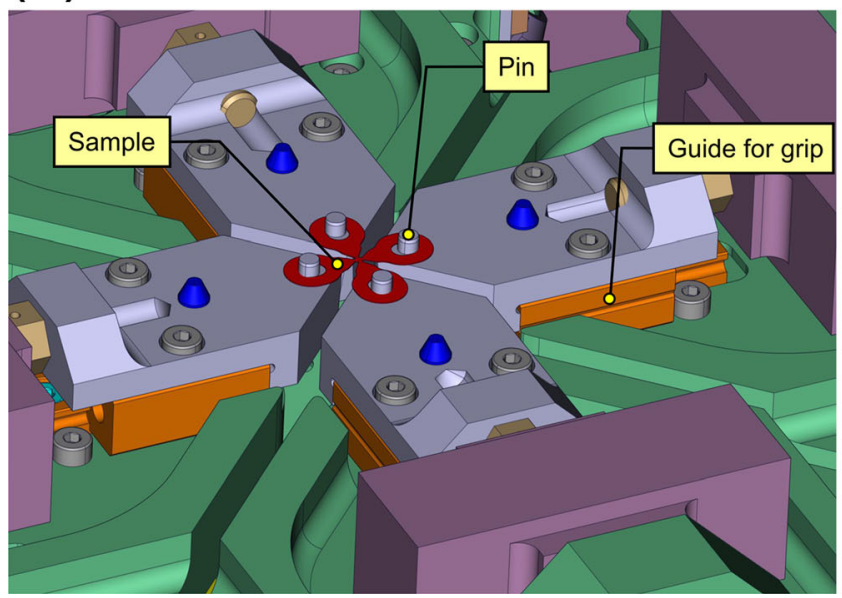

\section{Grip}
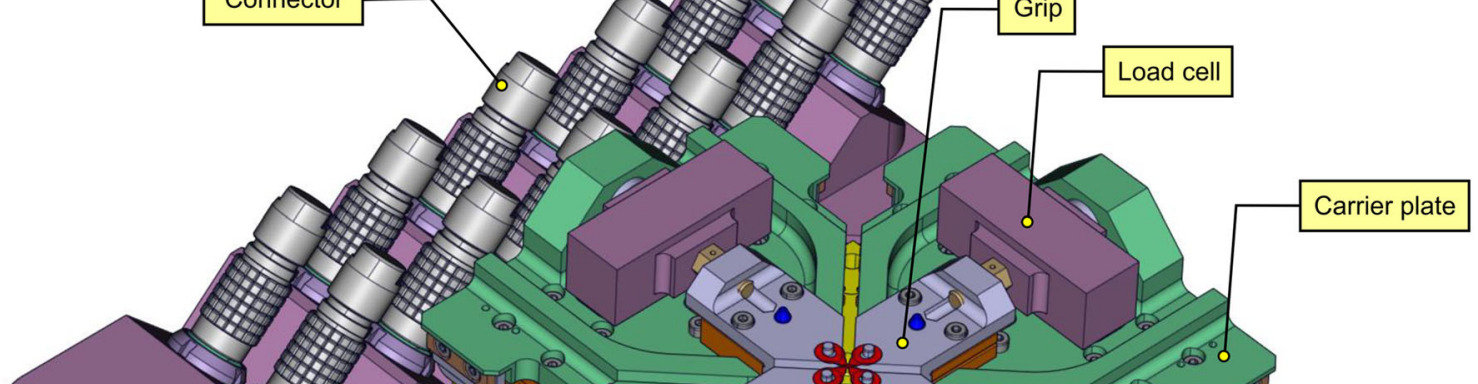

Cable housing
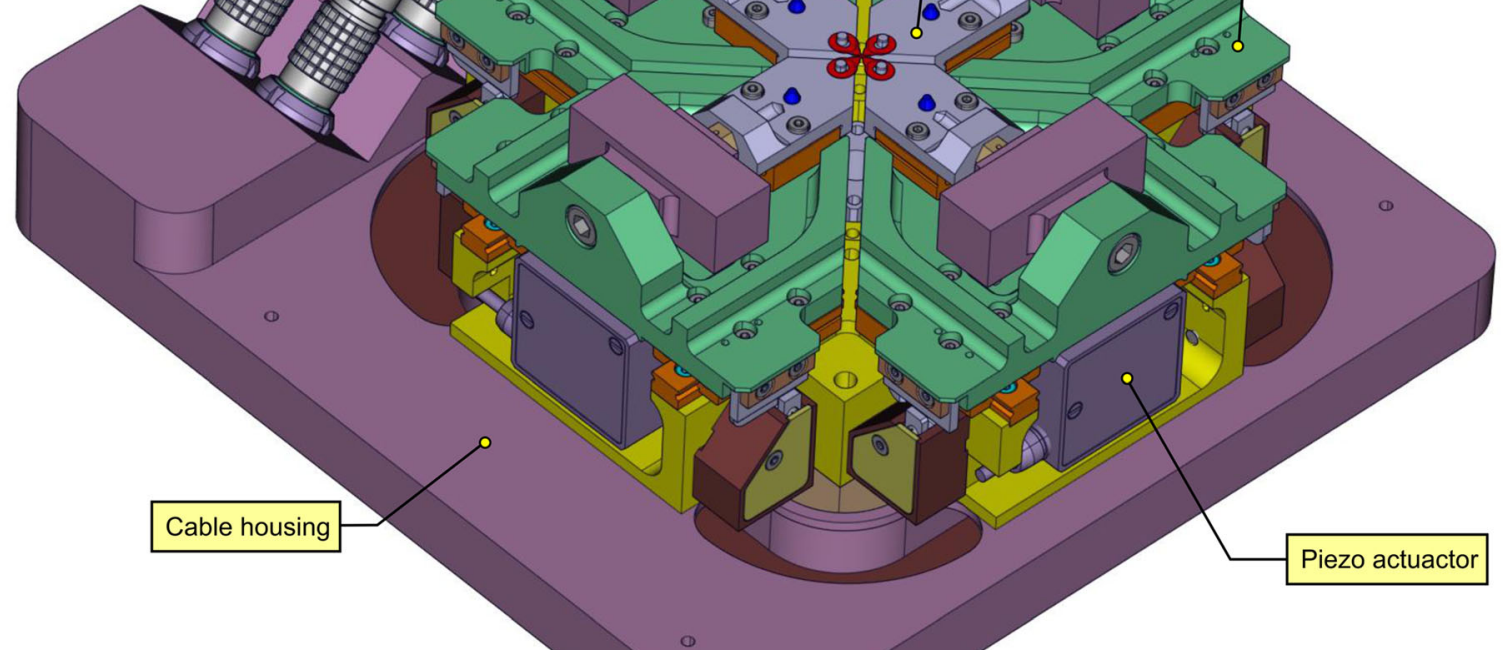

Fig. 1 (a) Schematic design of the in situ biaxial deformation device, (b) zoom on the sample mounted on the grips, (c) carrier plate (blue) with additional sensors connected to the grips

The traction system is mounted on a compact aluminium alloy frame, which also serves as housing for the cables. The outer dimensions of the complete setup are $200 \mathrm{~mm} \times 190 \mathrm{~mm} \times 73.2 \mathrm{~mm}$. The frame is open on the backside, which allows access of an X-ray beam to the centre of the specimen. The grips are designed such that the diffracted beam does not interfere with the apparatus. Each component is vacuum tight, which allows for safe operation inside an SEM chamber. Also, the grips and pins are designed such that the sample can be approached close enough to allow for high magnification imaging. 
Table 1 Parameters of the biaxial apparatus

\begin{tabular}{ll}
\hline Weight & $2.3 \mathrm{~kg}$ \\
Dimensions & $190 \mathrm{~mm} \times 200 \mathrm{~mm} \times 73.2 \mathrm{~mm}$ \\
Travel range per actuator & $10 \mathrm{~mm}$ \\
Maximum force per actuator & $44 \mathrm{~N}$ \\
Minimum step size per actuator & $10 \mathrm{~nm}$ \\
Stiffness actuators & $16 \mathrm{~N} / \mu \mathrm{m}$ \\
Resolution nano sensors & $1 \mathrm{~nm}$ \\
\hline
\end{tabular}

The compact design of the biaxial apparatus and its components result in a system with relatively low stiffness (see also section on machine characterisation). Furthermore the 4 axes are not perfectly identical due to mechanical tolerances. As a consequence, under load identical displacements of the actuators may result in slightly different motion of the grips. However, in order to avoid any bending of the cruciform shaped samples it is crucial that opposite grips exhibit exactly the same amount. Therefore, an additional system was designed, which allows monitoring the position of the grips with nanometre resolution. A plate (blue in Fig. 1(c)) with 4 linear guides with integrated encoders (GDW-1720-S, SmarAct) can be mounted on top of the machine. These guides are connected to pins mounted on the grips. When a grip moves, the connected guide moves parallel to it. In this way the encoder signal of the linear guides can be used as a measure for the motion of the grips. This additional position readout system cannot be used inside the SEM but it is compatible with in situ X-ray diffraction.

An E-712 controller (PI) drives the actuators and reads out the limit switches. The load cells are read out by TEDS readout panels (DPM-3, Transducer Techniques), that are connected by a serial device server (Moxa, Nport 5410). The encoders of the linear positioners are read out by nano position sensors (MCS-3S-ES-SDS15-TAB, SmarAct) connected to a sensor module (MCS-6CC-USB,
SmarAct). A custom-written LabVIEW program controls the complete setup.

\section{Installation in a Scanning Electron Microscope}

The rig has been designed for mounting in a conventional, regular sized SEM. An electrical feed-through flange was designed in order to have full control over the rig from outside the SEM. Figure 2(a) and (b) display, respectively, a schematic and a real-life image of the rig mounted in a Zeiss Ultra 55 SEM. The grips that hold the sample have been designed such that the minimum working distance is $7 \mathrm{~mm}$, which is sufficiently close for recording images with a resolution down to $5 \mathrm{~nm}$. The full travel range of the whole machine in the horizontal plane is $24 \mathrm{~mm}$. This allows obtaining images from areas away from the centre of the specimen. This is particularly useful for checking the quality of the sample mount or to control whether the sample has fractured at stress concentrations that may occur near the pins that hold the sample.

\section{Installation at the Synchrotron}

Figure 3 shows a technical drawing (Fig. 3(a) and (b) and a real image (Fig. 3(c)) of the biaxial machine attached to the goniometer of the powder diffraction station at the Materials Science (MS) beam line [37] of the Swiss Light Source (SLS). The machine is mounted on a rotational stage allowing positioning the rig for transmission (Fig. 3(a)) and reflection mode (Fig. 3(b)). Furthermore a translational stage with three degrees of freedom is used to place the centre of the sample at the position of the X-ray beam. The diffracted X-ray beam is detected by a one-dimensional (see Fig. 3(a)) or twodimensional detector located behind the device. The in situ $\mathrm{X}$-ray experiments can be performed with the additional carrier plate (see Fig. 1(c)). It has been designed such that the diffracted beam is not shadowed.
Fig. 2 A technical drawing (a) and real-life image (b) of the biaxial rig mounted inside a Zeiss Ultra 55 SEM (a)

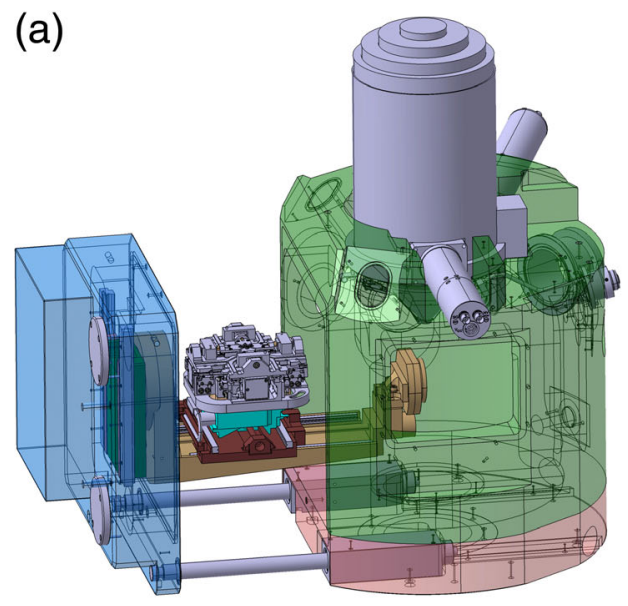

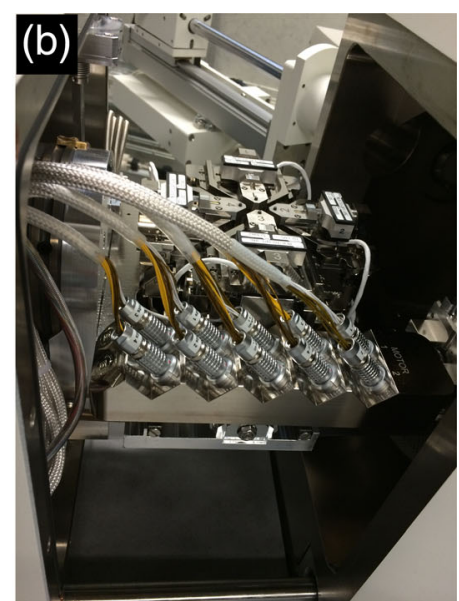



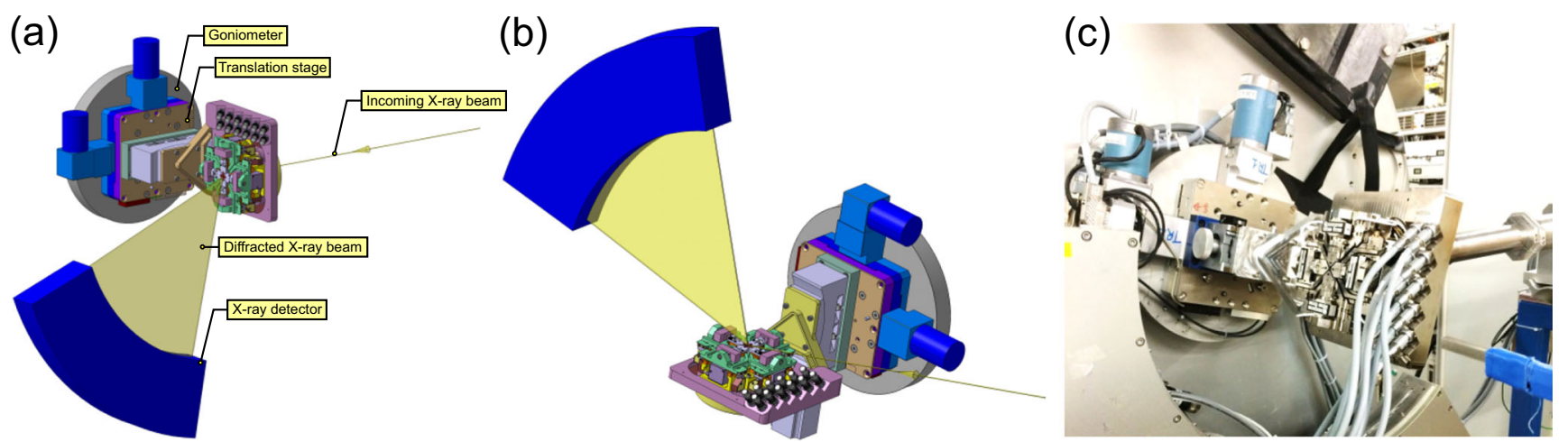

Fig. 3 Schematic drawing and real life image of the biaxial deformation rig mounted on the goniometer of the powder diffraction station at the MS beam line

\section{Specimen Geometry}

Defining the geometry of a cruciform shaped sample for biaxial testing is not straightforward [20, 22, 38-40]. It is the result of a trade-off between various considerations:

- At the centre the sample should not be thicker than a few tens of micrometres, in order to work in transmission with medium energy (5-25 keV) X-ray beams. This strongly depends on the absorption and scattering cross-section of the material used.

- The sample needs to be robust enough so that it can be handled and mounted in the test rig without affecting the local microstructure.

- Sufficient plasticity ( $>5 \%$ ) should occur in the central part of the sample prior to failure. The latter is particularly challenging, given the unavoidable stress concentrations at the crosssection of the arms of the cruciform sample [22, 38, 41].

- The stress state should be homogeneous within a central area with a diameter of $\sim 0.1 \mathrm{~mm}$.
The sample geometry has to be slightly tuned for each material, depending on its mechanical properties. The main parameters that are to be optimized include thickness of the arms, reduced thickness in the center, cross-arm shape and depth. In what follows experiments on an AlMg alloy are presented (see section on Mechanical Tests). Figure 4(a) displays a schematic of the corresponding sample geometry. In this particular case the shape was optimized for reaching high levels of plasticity during subsequent strain path changes with the aid of ABAQUS [42] finite element modelling (FEM). It has a width of $19 \mathrm{~mm}$ and an overall thickness of $0.2 \mathrm{~mm}$. The centre part is surrounded by 4 sharp corners and thinned down in several steps down to $50 \mu \mathrm{m}$ in a central circular area with a diameter of $400 \mu \mathrm{m}$. Figure 4(b), (c) and (d) show the results of an FEM simulation. Here the cruciform sample was strained uniaxially with constant strain rate up to $2.6 \%$ plastic strain in the gage section. Figure 4(b) displays the equivalent plastic strain, which shows that the plastic strain is concentrated in the central region. Figure 4(c) and (d) displays the two in-plane stress components, the out-of-plane stress component
Fig. 4 (a) Schematic drawing of the cruciform shaped specimen, (b)-(d) results from a FEM simulation of a uniaxial test up to $2.6 \%$ plastic strain showing (b) equivalent plastic strain, (c) stress component along the loading direction and (d) stress component perpendicular to the loading direction
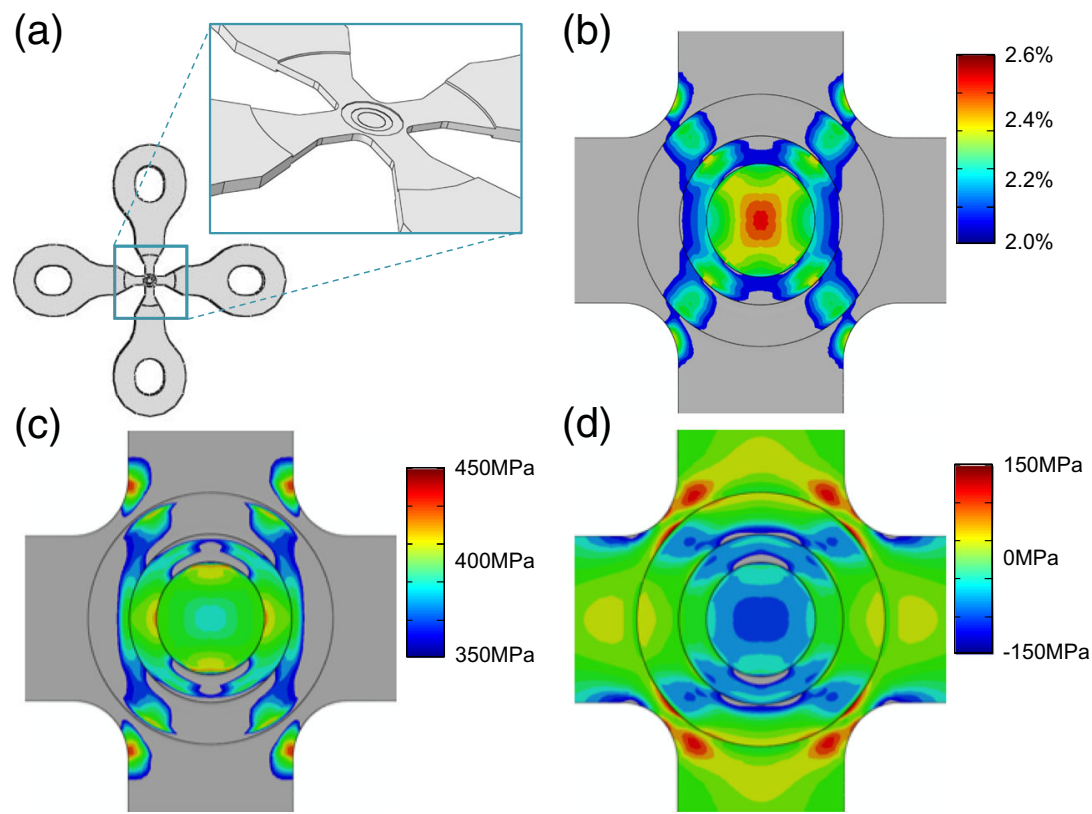
is negligible. Stress concentrations at the notches and at the steps are clearly visible. The stress state at the centre of the sample is however homogeneous. It is interesting to note that the stress component perpendicular to the loading direction is relatively high. This is related to the so-called "ring effect". It can be rationalized as follows: when applying a force along one particular axis, the thicker area surrounding the thin circular area in the centre induces an in-plane compressive stress perpendicular to the applied stress. The nature and magnitude of this stress strongly depends on the cruciform geometry. A detailed description of this complex phenomenon is beyond the scope of this paper. An in-depth discussion on this topic can be found in references [24, 41, 43, 44].

\section{Specimen Fabrication Procedure}

The cruciform specimens are machined using ultra-short pulsed laser ablation (PLA). Ultra-short PLA techniques use highly localized energy bursts to evaporate material, allowing the shaping of sub-micron structures with minimal residual damage $[45,46]$. For these samples, a pulsed laser with a $10 \mathrm{ps}$ pulse width is used. At this pulse width, ablation is known to be accompanied by the formation of a heat affected zone (HAZ), characterized by plasma formation and ejection of plasma from the surface [47]. However, by lowering the laser fluence to just above the ablation threshold fluence, the depth of the HAZ is minimized to insignificant levels ( $300 \mathrm{~nm}$ in a $50 \mu \mathrm{m}$ thick sample) [48]. Consequently, complex specimen shapes with reduced test sections can be made without causing significant damage in the test section. Figure 5 displays the sequential steps to fabricate the specimens.

1. Thin metal sheets (typical dimensions $50 \times 60 \times 0.2 \mu \mathrm{m}$ ) are cut by wire electrical discharge machining (Fig. 5(a)).

2. The test section is thinned down by PLA in 4 steps on one side of the sheet. Holes are cut through the sheet to allow for realignment of the sample on the other side (Fig. 5(b)).

3. The sheet is flipped, realigned, and the test section is milled on the other side (Fig. 5(c)).

4. The sample outline is cut from the sheet (Fig. 5(d) and (e)), and the sample is transferred to a special holder.

5. The arm holes and test section outline are cut at the same time, to ensure the test section is properly aligned (Fig. 5(f)).

6. The sample is transferred to a dedicated sample holder for transport.

Figure 5(g) Displays an SEM image of the gage section of an AlMg alloy. The periodic structure on the surface of the sample is due to the PLA technique. The observed features are of the order of a few hundred nanometres high and 5-10 $\mu \mathrm{m}$ wide. For most materials such small surface features are not expected to play an important role in the mechanical properties

An additional difficulty occurs when transferring the sample from one holder to another or to the biaxial apparatus. As
Fig. 5 Schematic overview of the sample preparation technique. For detailed explanation refer to the text

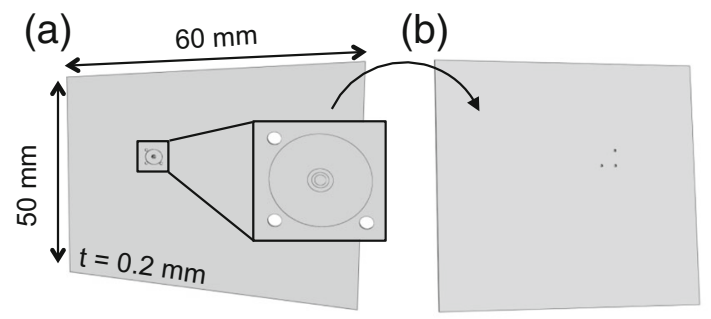

(c)

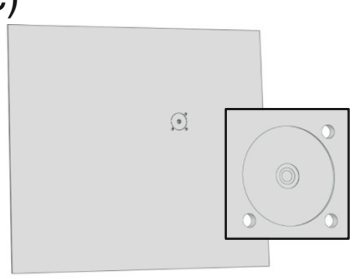

(d)

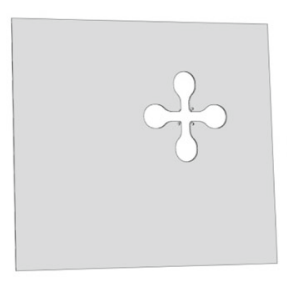

(g)

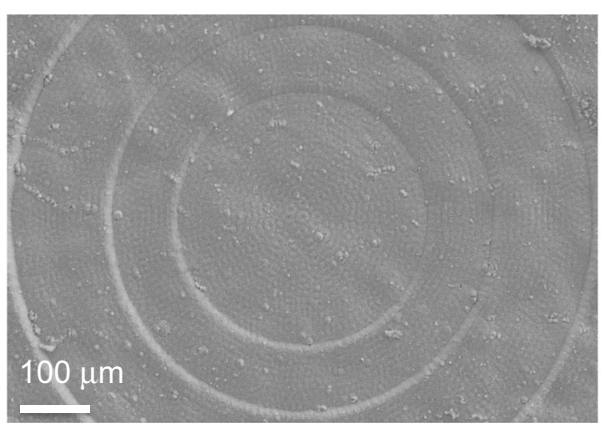

(f) (e)

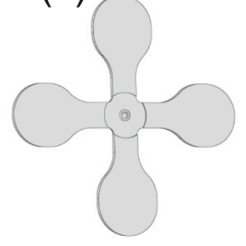

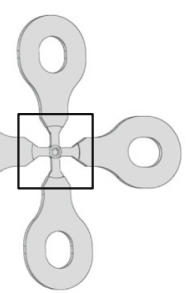


Fig. 6 Schematic drawings of (a) the sample transfer device, (b) sample holder

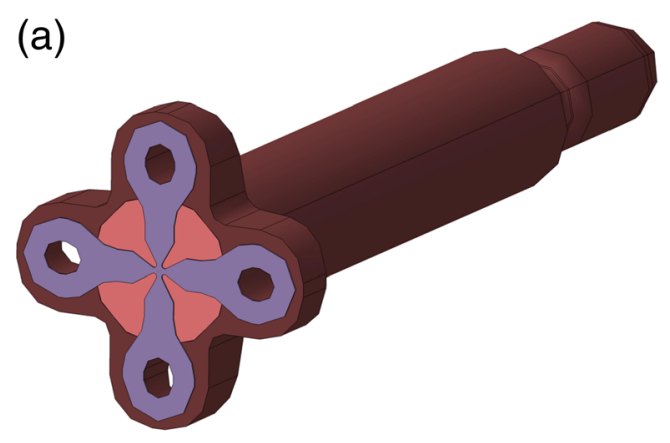

(b)

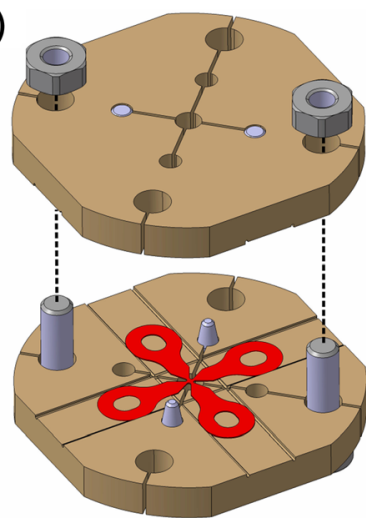

the samples are rather thin a clamping method (e.g. with tweezers) cannot be used, in particular for low strength materials such as, for instance, pure Al. Therefore a low-vacuum tool has been developed. A schematic view of this tool is shown in Fig. 6(a). Here the complete specimen is sucked against a flat surface. This allows a safe transfer and mounting of the samples. The samples are stored in a dedicated sample holder, as shown in Fig. 6(b). With the aid of the sample transfer device the sample can be placed accurately inside the grooves of sample holder.

\section{Application of the New Testing Setup}

\section{Machine Characterization}

\section{Machine compliance}

In order to determine the machine compliance experiments were performed with dog-bone shaped steel specimens. The specimens are strained in the elastic regime up to a force of $20 \mathrm{~N}$. The machine compliance is monitored by comparing the position of the piezo stage with that of the ears of the dog-bone sample. The latter is tracked by a high-resolution optical camera equipped with a telecentric lens. A non-negligible machine compliance of $\sim 2 \mathrm{~nm} / \mathrm{mN}$ was obtained, emphasizing the need for local monitoring of the grip positions, rather than relying on the position of the piezo stages.

\section{Sample - grip alignment}

The four piezo stages can move independent from each other. It is therefore crucial that the grips are aligned with high precision. Two independent criteria are used to verify the alignment. For the first test a cruciform shaped specimen is strained uniaxially. Here the two opposite piezo actuators on the primary axis exhibit the same displacement and the position of the other piezo actuators on the secondary axis remains fixed. Due to the Poisson response the sample contracts in the direction perpendicular to the loading axis, resulting in a tensile force along the secondary axis. When the sample is properly aligned the two force sensors of this secondary axis necessarily should show the same response. When this is not the case, the centre of the specimen does not perfectly coincide with the cross point of the two loading axes, which results in an additional tensile component in one actuator and a compressive component in the opposite actuator. This can resolved by the following procedure: the actuator of the secondary axis that exhibits the highest force is displaced towards the centre of the machine and simultaneously the actuator that exhibits the lowest force is displaced by equal amount away from the centre. This effectively moves the cross point of the two loading axis towards the centre of the specimen. This alignment procedure needs to be repeated for the second axis as well. Sometimes more than one iteration is needed.

The second criterion consist of a direct measurement of the centre of the sample by a high-resolution optical camera or inside an SEM. Figure 7 displays the position of the centre of a sample during straining to $10 \%$ plastic strain, tracked with an optical camera. In this particular case the sample remains stationary within the sensitivity of the measurement $(\sim 1 \mu \mathrm{m})$.

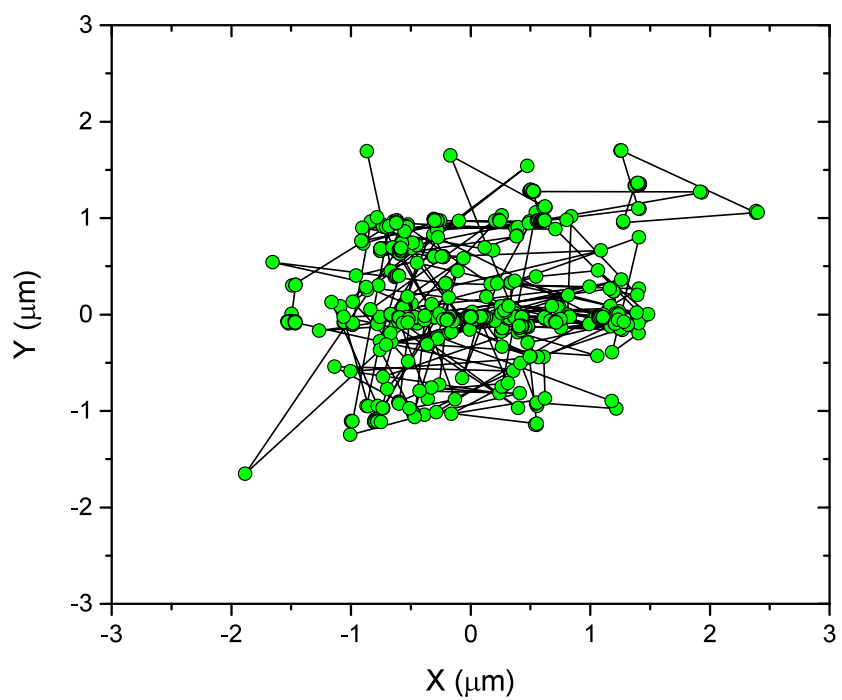

Fig. 7 Position of the centre of a cruciform shaped sample during straining up to $10 \%$ 
Table 2 Chemical composition of AlMg5

\begin{tabular}{lllllll}
\hline Element & $\mathrm{Al}$ & $\mathrm{Mg}$ & $\mathrm{Mn}$ & $\mathrm{Fe}$ & $\mathrm{Si}$ & Others \\
\hline wt\% & 94.3 & 5.33 & 0.16 & 0.12 & 0.07 & 0.02 \\
\hline
\end{tabular}

\section{Mechanical Tests}

Several deformation tests were performed on $\mathrm{Al}-5 \mathrm{wt} \% \mathrm{Mg}$ samples. The chemical composition as determined by optical emission spectroscopy is listed in Table 2. This material is known to exhibit the Portevin-Le Chatelier (PLC) effect [49, 50]. This is characterized by a serrated strain-stress response as a result of dynamic strain aging

A cruciform shaped specimen is subjected to uniaxial straining along the horizontal axis. Figure 8 displays a snapshot of the centre of the sample prior to the deformation and after $\sim 12 \%$ plastic strain. The centre of the sample exhibits three concentric circles due to the thickness reduction (see also Fig. 8(a)). In order to follow the deformation of the sample these features are simultaneously fitted with elliptical functions with a common centre, as indicated in yellow in Fig. 8(b) and (c). As expected, after plastic straining the circles have become ellipses (Fig. 8(c)). Two in-plane strain components are calculated as $\varepsilon_{\mathrm{hkl}}=\Delta \mathrm{L}_{\mathrm{h}, \mathrm{v}} / \mathrm{L}_{0}$ with $\mathrm{L}_{0}, \Delta \mathrm{L}_{\mathrm{h}}$ and $\Delta \mathrm{L}_{\mathrm{v}}$ the initial length and length change of the major (horizontal) and minor (vertical) axis of the ellipses, respectively. It should be noted that these strain values are only a rough estimation. In particular, it is assumed that the strain distribution within the inner ellipse is homogeneous, which is presumably not correct, as suggested by the FEM simulations shown in Fig. 4(b). More reliable measures for the strain can be obtained by performing the experiment in situ inside an SEM. With the aid of digital image correlation the actual strain distribution within the gauge area can be determined with high resolution (see, for instance, Refs. [51-54]). This is a matter of future research.

Figure 9 displays the evolution of the strain along the major and minor axes of the 3 ellipses as a function of time. Several interesting observations can be made:

- With decreasing thickness of the sample the amount of applied strain increases, as is witnessed by the larger

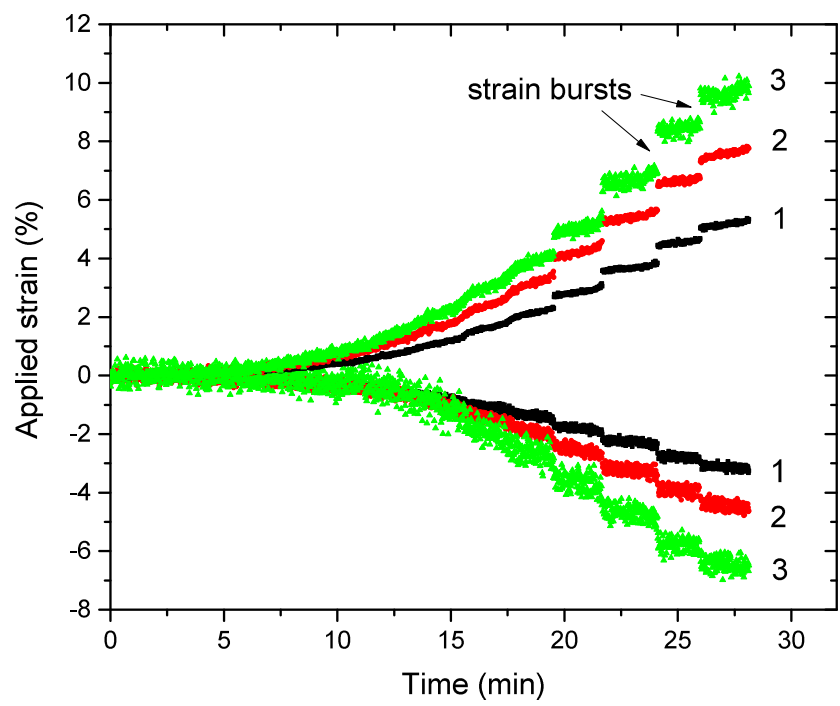

Fig. 9 Strain along the major and minor axes as determined by the fitting procedure shown in Fig 8(b) and (c). The numbers refer to the three circles shown in Fig. 8(b)

deformation of the inner circle. However, the deformation outside the inner circle cannot be neglected.

- The ratio between the strain along the minor and major axis is relatively large $(-0.63$ for the inner circle at the end of the test). This is clearly larger than the expected plastic Poisson's ratio and is the related to the ring effect, as discussed earlier in the section on Sample Geometry.

- The sample exhibits strain bursts characterized by sudden increases in strain along both major and minor axis (indicated by the arrows in Fig. 9), which can be related to the PLC effect.

Due to the complex geometry and the related ring effect the relationship between applied force and the local stress state at the centre of the sample cannot be expressed by analytical equations. Instead, FEM simulations are needed. ABAQUS/ Standard software [42] is used to perform the FE simulations for the cruciform and dog-bone samples. In order to improve the computational efficiency, only $1 / 8$ th of the entire geometry is simulated with symmetric boundary conditions on appropriate surfaces. A structured hexahedron mesh is employed with linear 8-node mesh elements (C3D8 in ABAQUS) for
Fig. 8 Optical image of the centre of the sample (a) and (b) before straining, (c) after uniaxial deformation along the horizontal axis. In (a) the intensity contrast forming the three inner circles are due to the thickness reduction. The yellow lines in (b) and (c) represent fits with elliptical functions
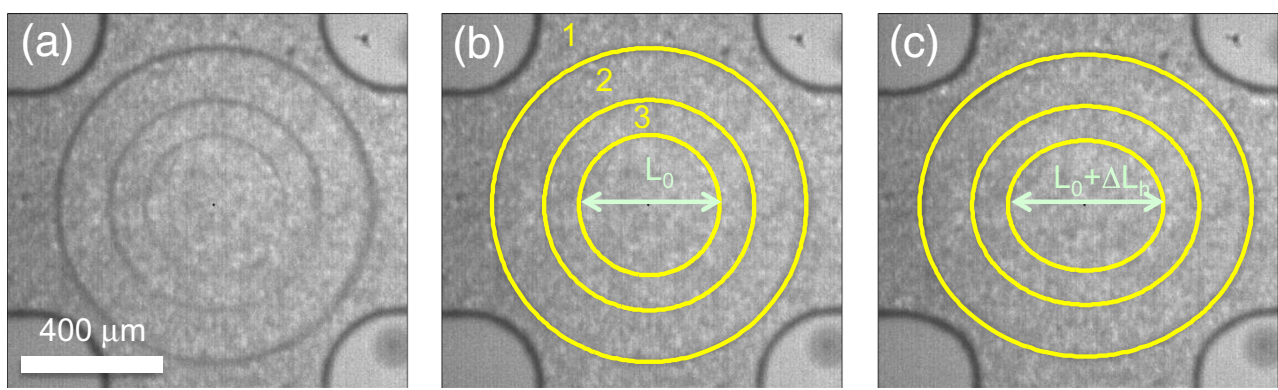


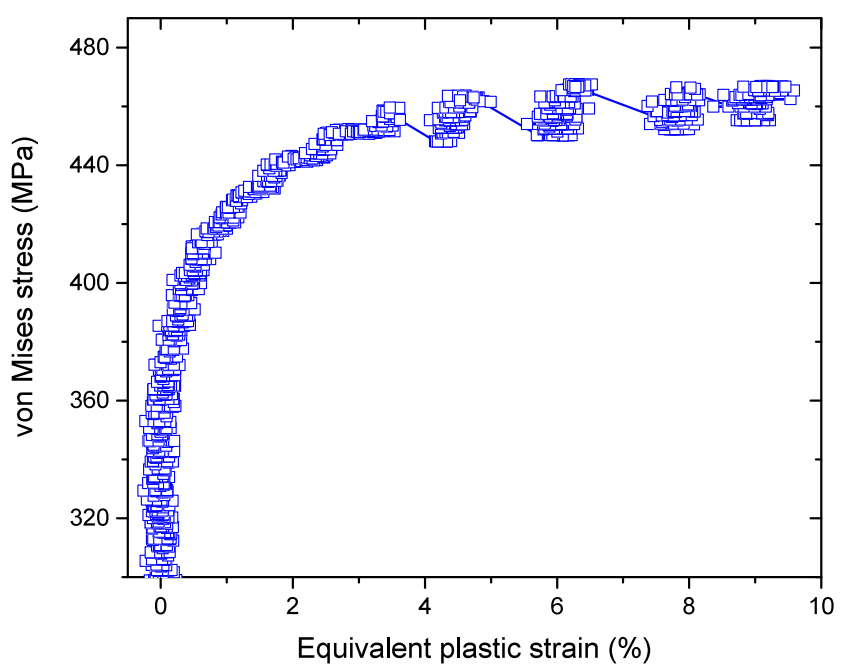

Fig. 10 Von Mises stress versus equivalent plastic strain during uniaxial straining of a cruciform shaped $\mathrm{Al}-5 \mathrm{wt} \% \mathrm{Mg}$ sample

both the cruciform and dog-bone geometries. Isotropic material properties of AlMg5 were used. The plastic response is modelled using the ABAQUS material model that is based on the von Mises yield criterion and the associated flow rule. The built-in rate-independent non-linear isotropic and kinematic hardening law with 5 back-stresses is used. It should be noted that such a simulation represents a first approximation only, as it does not account for, for instance, anisotropic material properties and relies on a phenomenological hardening law. In order to appropriately capture the multiaxial material behaviour crystal plasticity models are needed (see, for instance, Refs. [41, 55]). This is however beyond the scope of this paper.

The stress-strain response from a monotonic tensile loading test on a dog-bone sample is used as input to ABAQUS/ Standard. In order to account for micro-plasticity, the initial yield point is taken at $350 \mathrm{MPa}$. The ABAQUS/Standard algorithm uses this experimental curve to fit the back-stress parameters. Then the experiment with the cruciform is simulated. This results in a relationship between applied force and local stress at the centre of the cruciform specimen. With the relationship the experimentally measured applied force is converted into a von Mises stress. Figure 10 displays the resulting von Mises stress as a function of the equivalent plastic strain. It clearly shows the presence of stress drops and strain bursts, related to the PLC effect.

\section{Proof-Of-Principle in Situ Test}

An in situ proof-of-principle experiment was performed on the $\mathrm{Al}-5 \mathrm{wt} \% \mathrm{Mg}$ alloy at the MS beam line. The X-ray beam had a size of $\sim 80 \times 80 \mu \mathrm{m}^{2}$ and an energy of $17.5 \mathrm{keV}$. First, the sample was raster scanned in the beam with a step size of $50 \mu \mathrm{m}$ and the intensity of the transmitted beam is recorded by a diode placed behind the sample. The resulting transmission map recorded at the centre of the specimen is shown in Fig. 11(b). The transmission is normalized to that of air. The shape of the specimen shown in Fig. 11(a) can easily be recognized in the transmission map, which allows localizing the centre of the specimen with high precision.

We report here on the result of three continuous deformation tests: 1) uniaxial deformation of a standard dog-bone shape specimen, 2) uniaxial deformation of a cruciform shaped specimen and 3) equibiaxial straining of a cruciform shaped specimen. The scattering geometry for the tests is shown in Fig. 12. For test 1) the scattering vector $\mathbf{Q}$ (which is parallel to the normal of the diffracting planes) is perpendicular to the loading axis $\sigma_{22}$ (Fig. 12(a)). For tests 2) the cruciform shaped specimen is strained along axis $\sigma_{11}$, which is parallel to the scattering vector (Fig. 12(b)). For test 3 ) the cruciform shaped specimen is strained equally along both axes $\sigma_{11}$ and $\sigma_{22}$. Here the scattering vector is parallel to the direction $\sigma_{11}$ (Fig. 12(c)).

During straining high-resolution diffraction patterns were recorded continuously at a frequency of $0.05 \mathrm{~Hz}$. The diffraction peaks were fitted by asymmetric PVII functions. More details on the beam line and fitting procedures can be found in references [56, 57]. Elastic lattice strains $\varepsilon_{\mathrm{hkl}}$ were calculated from the evolution of the diffraction peak positions $\theta_{\mathrm{hk}}$ :

$\varepsilon_{h k l}=-\cot \left(\theta_{h k l}\right) \Delta \theta_{h k l}$
Fig. 11 Optical image (a) and the corresponding normalized transmission map (b) recorded at the centre of the cruciform shaped specimen
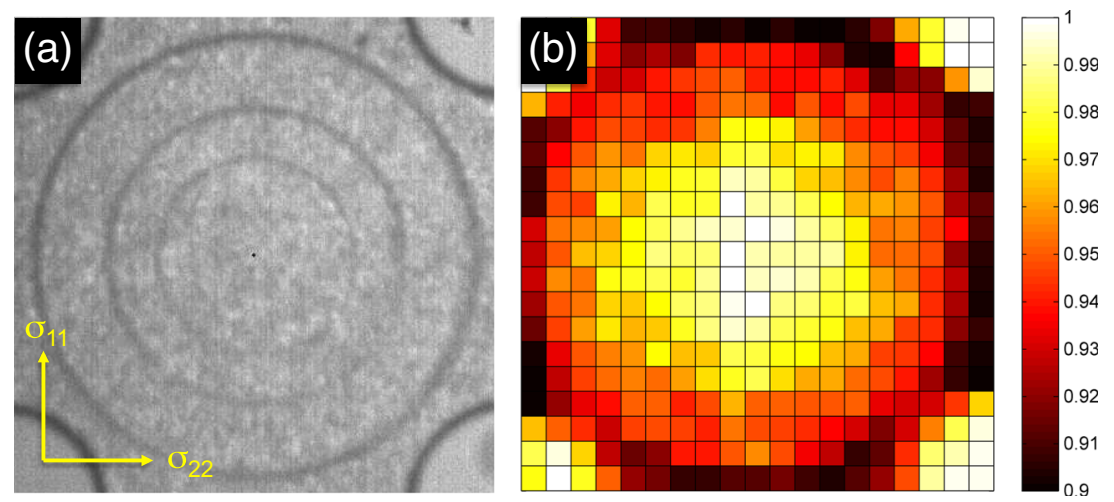
Fig. 12 Scattering geometry for the in situ mechanical tests. In (a) the scattering vector is perpendicular to the loading axis $\sigma_{22}$. In (b) the sample is strained along the axis $\sigma_{11}$, parallel to the scattering vector. In (c) both axes are strained equally, with the scattering vector parallel to axis $\sigma_{11}$

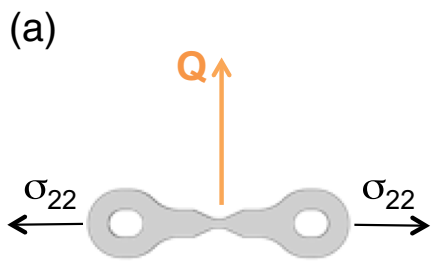

(b)

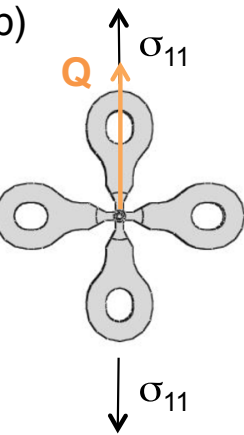

(c)

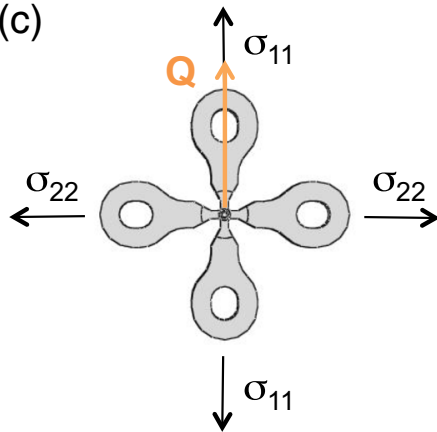

Figure 13 displays the evolution of the lattice strain derived from the $\{311\}$ diffraction peak as a function of applied stress for the three experiments. The stress is derived from the FEM simulations. Note that we restrict the discussion here to the elastic regime only. As expected, all curves exhibit a linear behaviour. The differences in slope can be rationalized by considering the analytical expressions that relate the applied stress $\sigma_{\mathrm{ij}}$ with elastic strain $\varepsilon_{\mathrm{ij}}$. For isotropic cubic materials this is given by the following Hooke's law [58]:

$\varepsilon_{i j}=\frac{1+\nu_{h k l}}{E_{h k l}} \sigma_{i j}-\delta_{i j} \frac{\nu_{h k l}}{E_{h k l}} \sigma_{k k}$

with $\gamma_{\mathrm{hkl}}$ and $\mathrm{E}_{\mathrm{hkl}}$ the hkl dependent Poisson's ratio and elastic modulus, respectively. It is well accepted [58] that for the $\{311\}$ diffraction peak the bulk elastic constants can be used: $v_{311}=0.335$ and $E_{311}=69 \mathrm{GPa}$. Considering only the strain component along the $\sigma_{11}$ axis (vertical axis in Fig. 12) and an in-plane biaxial stress state $\left(\sigma_{12}=\sigma_{21}=\sigma_{13}=\sigma_{31}=\sigma_{23}=\sigma_{32}=\sigma_{33}=0\right)$ this equation considerably simplifies to:

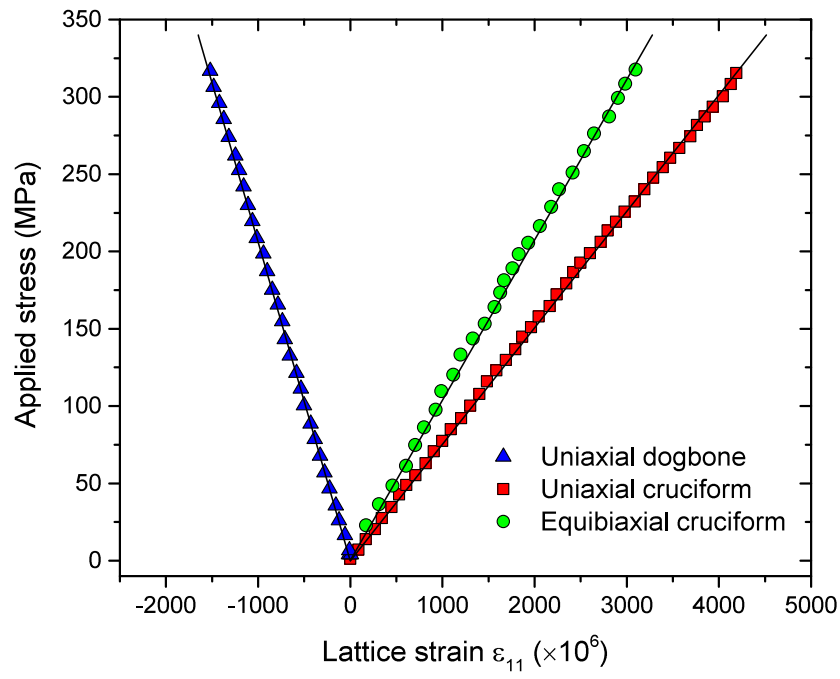

Fig. 13 Lattice strain $\left(\varepsilon_{11}\right)$ as derived from the $\{311\}$ diffraction peak as a function of applied stress component $\sigma_{11}$ for a uniaxial test on a dogbone and cruciform shaped sample, and for an equibiaxial test on a Al$5 \mathrm{wt} \% \mathrm{Mg}$ alloy $\varepsilon_{11}=\frac{1-r \nu}{E} \sigma_{11}$

$\varepsilon_{11}=\frac{r-\nu}{E} \sigma_{22}$

with $r$ the ratio between the two principle in-plane stress components $\sigma_{22}$ and $\sigma_{11}$. For tests 1) and 3) $r=0$ and $r=1$, respectively. The ratio $r$ for test 2 was obtained directly from the FEM simulations and is given by $r=-0.25$ (in the elastic regime). The resulting curves are shown in Fig. 13 by the solid lines. A very good match between the experimental and modeled data is obtained. This is a good indication that the finite element simulations capture well the geometrically induced complex stress states that arise at the centre of the cruciform shaped specimens.

\section{Conclusions}

In this work a miniaturized biaxial deformation rig was developed, that allows applying in-plane biaxial stress states and to perform strain path changes. The rig can be mounted inside conventional scanning electron microscope chambers and at synchrotron beam lines. The cruciform shaped sample geometry has been optimized with the aid of finite element simulations and allows reaching reasonable levels of plasticity. Sample preparation is challenging and requires the use of advanced preparation techniques. A proof-of-principle in situ Xray diffraction experiment revealed that the developed rig operates successfully. This will allow obtaining crucial microstructural information in real-time while the samples are subjected to complex biaxial strain paths.

Acknowledgements The authors gratefully acknowledge Antonio Cervellino and Michael Lange for their support with the setup at the Materials Science beamline, Stefan Ritter (Nuclear Energy and Safety, PSI) for his support with the setup at the SEM and Rolf Brönnimann (Reliability Science and Technology Laboratory, EMPA) for helping with sample preparation. HVS, AG, MD and MVU thank the European Research Council for the financial support within the advanced grant MULTIAX (339245). 
Open Access This article is distributed under the terms of the Creative Commons Attribution 4.0 International License (http:// creativecommons.org/licenses/by/4.0/), which permits unrestricted use, distribution, and reproduction in any medium, provided you give appropriate credit to the original author(s) and the source, provide a link to the Creative Commons license, and indicate if changes were made.

\section{References}

1. Schmitt JH, Aernoudt E, Baudelet B (1985) Yield loci for polycrystalline metals without texture. Mater Sci Eng 75:13-20. doi:10.1016/0025-5416(85)90173-9

2. Schmitt JH, Fernandes JV, Gracio JJ, Vieira MF, Vieira MF (1991) Plastic behaviour of copper sheets during sequential tension tests. Mater Sci Eng A 147:143-154. doi:10.1016 /0921-5093(91)90840-J

3. Peeters B, Kalidindi SR, Van Houtte P, Aernoudt E (2000) A crystal plasticity based work-hardening/softening model for b.c.c. metals under changing strain paths. Acta Mater 48:2123-2133. doi:10.1016/S1359-6454(00)00047-1

4. Barlat F, Ferreira Duarte JM, Gracio JJ, Lopes AB, Rauch EF (2003) Plastic flow for non-monotonic loading conditions of an aluminum alloy sheet sample. Int J Plast 19:1215-1244. doi:10.1016/S0749-6419(02)00020-7

5. Beyerlein IJ, Tomé CN (2007) Modeling transients in the mechanical response of copper due to strain path changes. Int J Plast 23: 640-664. doi:10.1016/j.ijplas.2006.08.001

6. Banabic PDID (2010) Plastic behaviour of sheet metal. In: Sheet Met. Form. Process. Springer, Berlin, pp. 27-140 http://link. springer.com/chapter/10.1007/978-3-540-88113-1_2. Accessed 30 June 2016

7. Barlat F (2007) Constitutive modeling for metals. Adv. Methods Mater. Form. Springer, Berlin, In, pp. 1-18 http://link.springer. com/chapter/10.1007/3-540-69845-0_ 1. Accessed 30 June 2016

8. Fernandes JV, Gracio JJ, Schmitt JH, Rauch EF (1993) Development and persistence of microbands in copper deformed under complex strain paths. Scr Metall Mater 28:1335-1340. doi:10.1016/0956-716X(93)90478-B

9. Wilson DV, Bate PS (1994) Influences of cell walls and grain boundaries on transient responses of an if steel to changes in strain path. Acta Metall Mater 42:1099-1111. doi:10.1016/0956-7151(94 )90127-9

10. Wilson DV, Bate PS (1996) Internal elastic strains in an IF steel following changes in strain path. Acta Mater 44:3371-3383. doi:10.1016/1359-6454(95)00427-0

11. Tasan CC, Hoefnagels JPM, Dekkers ECA, Geers MGD (2011) Multi-axial deformation setup for microscopic testing of sheet metal to fracture. Exp Mech 52:669-678. doi:10.1007/s11340-011-9532-x

12. Benedetti M, Fontanari V, Bandini M, Taylor D (2014) Multiaxial fatigue resistance of shot peened high-strength aluminum alloys. Int J Fatigue 61:271-282. doi:10.1016/j.ijfatigue.2013.10.020

13. Klitschke S, Boehme W (2016) Deformation and damage behavior of lightweight steels at high rate multiaxial loading. Mater Test 58: 173-181. doi:10.3139/120.110836

14. Ranta-Eskola AJ (1979) Use of the hydraulic bulge test in biaxial tensile testing. Int J Mech Sci 21:457-465. doi:10.1016/0020-7403 (79)90008-0

15. Rees DWA (1995) Plastic flow in the elliptical bulge test. Int J Mech Sci 37:373-389. doi:10.1016/0020-7403(94)00071-Q

16. Marciniak Z, Kuczyński K (1967) Limit strains in the processes of stretch-forming sheet metal. Int J Mech Sci 9:609-620. doi:10.1016 /0020-7403(67)90066-5
17. Raghavan KS (1995) A simple technique to generate in-plane forming limit curves and selected applications. Metall Mater Trans A 26:2075-2084. doi:10.1007/BF02670679

18. Lee Y-W, Woertz JC, Wierzbicki T (2004) Fracture prediction of thin plates under hemi-spherical punch with calibration and experimental verification. Int J Mech Sci 46:751-781. doi:10.1016/j. ijmecsci.2004.05.004

19. Barlat F, Becker RC, Hayashida Y, Maeda Y, Yanagawa M, Chung K, Brem JC, Lege DJ, Matsui K, Murtha SJ, Hattori S (1997) Yielding description for solution strengthened aluminum alloys. Int J Plast 13:385-401. doi:10.1016/S0749-6419(97)80005-8

20. Kuwabara T, Ikeda S, Kuroda K (1998) Measurement and analysis of differential work hardening in cold-rolled steel sheet under biaxial tension. J Mater Process Technol 80-81:517-523. doi:10.1016 /S0924-0136(98)00155-1

21. Kuwabara T, Kuroda M, Tvergaard V, Nomura K (2000) Use of abrupt strain path change for determining subsequent yield surface: experimental study with metal sheets. Acta Mater 48:2071-2079. doi:10.1016/S1359-6454(00)00048-3

22. Demmerle S, Boehler JP (1993) Optimal design of biaxial tensile cruciform specimens. J Mech Phys Solids 41:143-181. doi:10.1016 /0022-5096(93)90067-P

23. Gozzi J, Olsson A, Lagerqvist O (2005) Experimental investigation of the behavior of extra high strength steel. Exp Mech 45:533-540. doi:10.1007/BF02427907

24. Van Petegem S, Wagner J, Panzner T, Upadhyay MV, Trang TTT, Van Swygenhoven H (2016) In-situ neutron diffraction during biaxial deformation. Acta Mater 105:404-416. doi:10.1016/j. actamat.2015.12.015

25. Repper J, Niffenegger M, van Petegem S, Wagner W, van Swygenhoven H (2013) Biaxial mechanical testing at the neutron time-of-flight diffractometer POLDI. Mater Sci Forum 768-769: 60-65. doi:10.4028/www.scientific.net/MSF.768-769.60

26. Hannon A, Tiernan P (2008) A review of planar biaxial tensile test systems for sheet metal. J Mater Process Technol 198:1-13. doi:10.1016/j.jmatprotec.2007.10.015

27. Foecke T, Iadicola MA, Lin A, Banovic SW (2007) A method for direct measurement of multiaxial stress-strain curves in sheet metal. Metall Mater Trans A 38:306-313. doi:10.1007/s11661-006-9044-y

28. Iadicola MA, Foecke T, Banovic SW (2008) Experimental observations of evolving yield loci in biaxially strained AA5754-O. Int J Plast 24:2084-2101. doi:10.1016/j.ijplas.2008.03.003

29. Iadicola MA, Hu L, Rollett AD, Foecke T (2012) Crystal plasticity analysis of constitutive behavior of 5754 aluminum sheet deformed along bi-linear strain paths. Int J Solids Struct 49:3507-3516. doi:10.1016/j.ijsolstr.2012.03.015

30. Iadicola MA, Creuziger AA, Foecke T (2014) Advanced biaxial cruciform testing at the NIST Center for Automotive Lightweighting. In: Rossi M, Sasso M, Connesson N, Singh R, DeWald A, Backman D, Gloeckner P (eds) Residual stress thermomechanics infrared imaging hybrid Tech. Inverse Probl., Vol. 8. Springer International Publishing, pp. 277-285. http://ink. springer.com/chapter/10.1007/978-3-319-00876-9_34. Accessed 30 June 2016

31. Hoefnagels JPM, Tasan CC, Dekkers ECA, Geers MGD (2010) Miniature Marciniak setup for in-situ SEM observation of damage micro-mechanisms. EPJ Web Conf 6:16009. doi:10.1051 /epjconf/20100616009

32. Geandier G, Thiaudière D, Randriamazaoro RN, Chiron R, Djaziri S, Lamongie B, Diot Y, Bourhis EL, Renault PO, Goudeau P, Bouaffad A, Castelnau O, Faurie D, Hild F (2010) Development of a synchrotron biaxial tensile device for in situ characterization of thin films mechanical response. Rev Sci Instrum 81:103903. doi: $10.1063 / 1.3488628$ 
33. Djaziri S, Faurie D, Renault P-O, Le Bourhis E, Goudeau P, Geandier G, Thiaudière D (2013) Yield surface of polycrystalline thin films as revealed by non-equibiaxial loadings at small deformation. Acta Mater 61:5067-5077. doi:10.1016/j. actamat.2013.04.031

34. Brieu M, Diani J, Bhatnagar N (2007) New biaxial tension test fixture for uniaxial testing machine - a validation for hyperelastic behavior of rubber-like materials. J Test Eval 35:364-372

35. Collins DM, Mostafavi M, Todd RI, Connolley T, Wilkinson AJ (2015) A synchrotron X-ray diffraction study of in situ biaxial deformation. Acta Mater 90:46-58. doi:10.1016/j. actamat.2015.02.009

36. Hommer GM, Park JS, Collins PC, Pilchak AL, Stebner AP (2017) A new in situ planar biaxial far-field high energy diffraction microscopy experiment. In: Yoshida S, Lamberti L, Sciammarella C (eds) Adv. Opt. Methods Exp, Mech., Vol., vol 3. Springer International Publishing, Cham, pp. 61-70 http://link.springer.com/10.1007/9783-319-41600-7 7. Accessed 14 Nov 2016

37. Willmott PR, Meister D, Leake SJ, Lange M, Bergamaschi A, Böge M, Calvi M, Cancellieri C, Casati N, Cervellino A, Chen Q, David C, Flechsig U, Gozzo F, Henrich B, Jäggi-Spielmann S, Jakob B, Kalichava I, Karvinen P, Krempasky J, Lüdeke A, Lüscher R, Maag S, Quitmann C, Reinle-Schmitt ML, Schmidt T, Schmitt B, Streun A, Vartiainen I, Vitins M, Wang X, Wullschleger R (2013) The materials science beamline upgrade at the Swiss light source. J Synchrotron Radiat 20:667-682. doi:10.1107 /S0909049513018475

38. Quaak G (2008) Biaxial testing of sheet metal: an experimentalnumerical analysis. Eindhoven University of Technology, Master thesis

39. Upadhyay M, Panzner T, Van Petegem S, Van Swygenhoven H (2017) Stresses and strains in cruciform samples deformed in tension. Rev

40. Hommer GM, Stebner AP (2016) Development of a specimen for in-situ diffraction planar biaxial experiments. In: Beese AM, Zehnder AT, Xia S (eds) Fract. Fatigue Fail. Damage Evol., Vol. 8. Springer International Publishing, pp. 45-50. http://link.springer. com/chapter/10.1007/978-3-319-21611-9_6. Accessed 19 Aug 2016

41. Upadhyay MV, Van Petegem S, Panzner T, Lebensohn RA, Van Swygenhoven H (2016) Study of lattice strain evolution during biaxial deformation of stainless steel using a finite element and fast Fourier transform based multi-scale approach. Acta Mater 118:28 43. doi:10.1016/j.actamat.2016.07.028

42. Dassault Systèmes Providence RI (USA) (2011), Abaqus Documentation

43. Cláudio RA, Reis L, Freitas M (2014) Biaxial high-cycle fatigue life assessment of ductile aluminium cruciform specimens. Theor Appl Fract Mech 73:82-90. doi:10.1016/j.tafmec.2014.08.007

44. Bonnand V, Chaboche JL, Gomez P, Kanouté P, Pacou D (2011) Investigation of multiaxial fatigue in the context of turboengine disc applications. Int J Fatigue 33:1006-1016. doi:10.1016/j. ijfatigue.2010.12.018
45. Knowles MRH, Rutterford G, Karnakis D, Ferguson A (2007) Micro-machining of metals, ceramics and polymers using nanosecond lasers. Int J Adv Manuf Technol 33:95-102. doi:10.1007 /s00170-007-0967-2

46. Shaheen ME, Gagnon JE, Fryer BJ (2013) Laser ablation of iron: a comparison between femtosecond and picosecond laser pulses. J Appl Phys 114:083110. doi:10.1063/1.4819804

47. Schäfer C, Urbassek HM, Zhigilei LV (2002) Metal ablation by picosecond laser pulses: A hybrid simulation. Phys Rev B 66 . doi:10.1103/PhysRevB.66.115404

48. Guitton A, Irastorza-Landa A, Broennimann R, Grolimund D, Van Petegem S, Van Swygenhoven H (2015) Picosecond pulsed laser for microscale sample preparation. Mater Lett 160:589-591. doi:10.1016/j.matlet.2015.06.119

49. Yilmaz A (2011) The Portevin-Le Chatelier effect: a review of experimental findings. Sci Technol Adv Mater 12:063001. doi:10.1088/1468-6996/12/6/063001

50. Portevin AA, Le Chatelier H (1924) Heat treatment of aluminiumcopper alloys. Trans Am Soc Steel Treat 5:457-478

51. Di Gioacchino F, Quinta da Fonseca J (2013) Plastic strain mapping with sub-micron resolution using digital image correlation. Exp Mech 53:743-754. doi:10.1007/s11340-012-9685-2

52. Sutton MA, Li N, Joy DC, Reynolds AP, Li X (2007) Scanning electron microscopy for quantitative small and large deformation measurements part I: SEM imaging at magnifications from 200 to 10,000. Exp Mech 47:775-787. doi:10.1007/s11340-007-9042-Z

53. Sutton MA, Li N, Garcia D, Cornille N, Orteu JJ, McNeill SR, Schreier HW, Li X, Reynolds AP (2007) Scanning electron microscopy for quantitative small and large deformation measurements part II: experimental validation for magnifications from 200 to 10 , 000. Exp Mech 47:789-804. doi:10.1007/s11340-007-9041-0

54. Walley JL, Wheeler R, Uchic MD, Mills MJ (2011) In-situ mechanical testing for characterizing strain localization during deformation at elevated temperatures. Exp Mech 52:405-416. doi:10.1007 /s11340-011-9499-7

55. Prakash A, Nöhring WG, Lebensohn RA, Höppel HW, Bitzek E (2015) A multiscale simulation framework of the accumulative roll bonding process accounting for texture evolution. Mater Sci Eng A 631:104-119. doi:10.1016/j.msea.2015.02.005

56. Budrovic Z, Swygenhoven HV, Derlet PM, Petegem SV, Schmitt B (2004) Plastic deformation with reversible peak broadening in Nanocrystalline nickel. Science 304:273-276. doi:10.1126 /science.1095071

57. Van Swygenhoven H, Schmitt B, Derlet PM, Van Petegem S, Cervellino A, Budrovic Z, Brandstetter S, Bollhalder A, Schild M (2006) Following peak profiles during elastic and plastic deformation: a synchrotron-based technique. Rev Sci Instrum 77:013902. doi:10.1063/1.2162453

58. Fitzpatrick M, Lodini A (2003) Analysis of residual stress by diffraction using neutron and synchrotron radiation. Taylor \& Francis, London 